\title{
Implementation of Shared Decision-Making in Australia
}

\author{
K Ervin, I Blackberry and $\mathrm{H}$ Haines
}

\begin{abstract}
Shared decision-making (SDM) is the process of clinicians and patients participating jointly in making healthcare decisions, having discussed evidence-based treatment options and the potential risks and benefits of each option, taking into consideration the patient's individual preferences and values. SDM is ubiquitous in Australian healthcare policy. While there is good evidence for utilising SDM, clinicians' knowledge of SDM, the current uptake, effectiveness and acceptability
\end{abstract}

of SDM in Australia is largely unknown. The challenges perceived by clinicians to implementing SDM in clinical practice and potential moral, legal and ethical dilemmas require further debate and consideration.

Abbreviations: SDM - Shared Decision-Making.

Key words: shared decision-making; implementation; policy.

\section{Kaye E Ervin}

La Trobe University Albury-Wondonga Campus

Ringgold Standard Institution

Wodonga, Victoria, Australia.

\section{Irene Blackberry}

La Trobe University Albury-Wondonga Campus

Ringgold Standard Institution

Wodonga, Victoria, Australia.

\section{Helen Haines}

University of Melbourne

Rural Health Academic Network

Shepparton, Victoria, Australia.

Correspondence:

ervink@humehealth.org.au

The principles of shared decision-making (SDM) are essential in healthcare delivery and aim at developing a genuinely patient-focused healthcare system. [1] Evidence suggests SDM reduces healthcare costs and variations in care while increasing patient compliance and satisfaction with treatment. [2] Urgent and widespread implementation of SDM in all healthcare settings has been advocated in Australia, [3] including Australian healthcare policy. [4] Despite emerging evidence of successful SDM models and their benefit internationally, [5] there are also many challenges and careful consideration needs to be exercised in the widespread implementation in clinical practice in
Australia. Few training opportunities in SDM currently exist for clinicians, either at postgraduate level or continuing professional development. [3] This may pose a risk of an ad hoc implementation by ill-equipped clinicians, who increasingly provide care to patients with multi-morbidity.

Coulter and Collins [5] describe three essential components of shared decision-making:

- The patient is provided with current, unbiased evidencebased information about potential care, support or treatment, clarifying outcomes or uncertainties;

- There is decision support counselling with a clinician to clarify options and patient preferences; and

- There is a robust system to record patient preferences, communicate them to others and to implement the preferred choice.

Discrepancies exist between clinicians' self-reported use of SDM and observations of usual care. [1] One of the criticisms of SDM is the perceived time required to practise SDM with patients, in settings that are already time poor with clinicians overextended. $[6,7]$ There are conflicting opinions among researchers about whether additional time is required to implement SDM. $[3,6]$ Clinicians cite time constraints as the most frequently anticipated barrier to SDM [8] and policy or research has not satisfactorily addressed this. Time constraints do not simply relate to the decision-making process with patients, but also the time required to access 
up-to-date research evidence, which may not always be readily accessible for clinicians, for specific treatment under consideration.

Additional challenges which need to be addressed include how clinicians can use the SDM process with patients who have cognitive deficits $[9,10]$ or low levels of health literacy. [11] Patients with diminished capacity add another layer of complexity to the SDM process for clinicians. [12] Clinicians must determine who can legally act as a surrogate decision maker, which is not always clear and may require time and skills from the clinician. [12] Further considerations include the surrogates' willingness to be involved, [13] and their intention to act in the best interests of the patient. [14]

The Australian Council on Health Standards [4] advocates for the implementation of SDM by all clinicians in all healthcare settings. The process of SDM conflicts with some current government directives and legislation that abrogate patient choice, such as childhood immunisation, male/female circumcision and euthanasia. This presents moral, ethical and legal dilemmas for clinicians, with no clear directives on how these are to be resolved. There is a tension for clinicians between adhering to clinical guidelines and law and respecting a patient's treatment preferences. [15]

Existing activity demonstrates Australian government agencies commitment to SDM by incorporating principles into policy, guidelines and planned training programs. $[4,16,17]$ However, further research is warranted in all healthcare settings, for all disciplines, to complement emerging policy initiatives and to determine resource needs.

Over the past decade, a large gap between theory and practice of SDM continues. [8] The uptake of SDM in Australia, clinicians' knowledge of SDM and the level of preferred patient involvement are largely unknown. Rather than acting urgently as suggested, [3] more debate is warranted regarding training requirements and adequate support to implement a SDM process that is acceptable to both clinicians and patients according to ethical principles. Australian health policy should encompass a nationwide and co-ordinated approach in research, training and professional development in SDM.

\section{Competing interests}

The authors declare that they have no competing interests.

\section{References}

1. King J, Moulton B. Rethinking informed consent: the case for shared medical decision-making. Am J Law Med. 2006;32(4): 429-501.

2. O'Connor A, Bennett C, Stacey D, Barry M, Col N, Eden B, et al. Decision aids for people facing health treatment or screening decisions. Cochrane Database Syst Rev. 2009;3(CD0011431).

3. Hoffmann T, Légaré F, Simmons M, McNamara K, McCaffery K, Trevena L, et al. Shared decision-making: what do clinicians need to know and why should they bother? Med J Aust. 2014;201(1): 35-39.

4. Australian Commision on Safety and Quality in Healthcare: National Standards and Accreditation. Available from: www.safety andqualitygovau/our-work/shared-decision-making 2015.

5. Coulter A, Collins A. Making shared decision-making a reality. No decision about me, without me. Kings Fund. 2011. Available from: http://www.kingsfund.org.uk/publications/nhs_ decisionmaking.html.

6. Bernard A. Shared decision-making reduces antibiotic overuse. Medscape Education. 2015, Clinical briefs.

7. Fetherstonhaugh D, Tarzia L, Bauer M, Nay R, Beattie E. “The Red Dress or the Blue?": How do staff perceive that they support decision-making for people with dementia living in residential aged care facilities? J Appl Gerontol. 2014;35(2):209-226.

8. Godolphin W. Shared decision-making. Healthc Q. 2009;12(Special issue):186-190.

9. Yates M. Why do we need to improve dementia care in acute hospitals? Dementia Care in Hospitals Symposium, Sydney 2014.

10. Lally J, Tullo E. Engaging older people in decisions about their healthcare: the case for shared decision-making. Rev Clin Gerontol. 2012;22(2):99-107.

11. Colyer S. Doctors care but do they share? Med J Aust. Insight. July; 2014.

12. Armstrong R. Sharing and caring. Med J Aust. Insight. Jan: 2014 ,

13. Clark N, Nelson B, Valero M, Gong Z, Taylor-Fishwick J, Fletcher M. Consideration of shared decision-making in nursing: a review of clinicians' perceptions and interventions. Open Nurs J. 2009;3:65-75.

14. Smith A, Lo B, Sudore R. When previously expressed wishes conflict with best interests. JAMA Intern Med. 2013; 173(13):1241-1245.

15. Boivin A, Legare F, Gagnon M. Competing norms: Canadian rural family physicians' perceptions of clinical practice guidelines and shared decision-making. Health Service Res Policy. 2008;13(2): 79-84.

16. RACGP. Clinical guidelines. Available from: http://www.racgp.org. au/your-practice/guidelines/drugs-ofdependence-a/5-patientfocus51-shared-decision-making/

17. McCoy R. Royal Australian College of General Practitioners. RACGP curriculum for Australian general practice. Available from: www. safetyandquality.gov.au/.../Ronald-McCoy-Shared-decisionmakingin-Australia. 2011. 